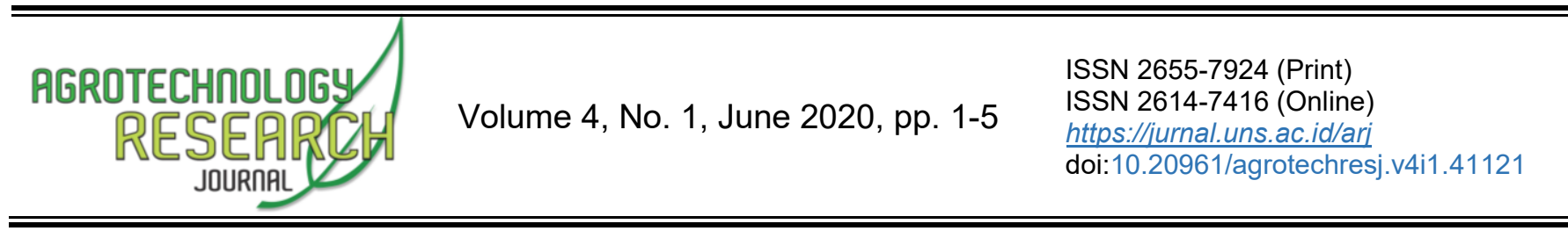

\title{
Pengaruh Aplikasi Tandan Kosong Kelapa Sawit dan Arang Sekam Padi terhadap Beberapa Sifat Kimia Tanah pada Tomat
}

\author{
Fitra Syawal Harahap ${ }^{1 *}$, Hilwa Walida ${ }^{2}$, Rahmaniah $^{3}$, Abdul Rauf $^{4}$, Rosmidah Hasibuan $^{5}$, Ade Parlaungan \\ Nasution 6 \\ ${ }^{1-2}$ Department of Agrotechnology, Faculty of Science and Technology, Universitas Labuhanbatu, Labuhanbatu, Indonesia \\ ${ }^{3}$ Department of Agrotechnology, Faculty of Agriculture, Universitas Pembinaan Masyarakat Indonesia, Medan, Indonesia \\ ${ }^{4}$ Department of Agrotechnology, Faculty of Agriculture, Universitas Sumatera Utara, Medan, Indonesia \\ ${ }^{5}$ Department of Biology Education, Faculty of Teachership and Education, Universitas Labuhanbatu, Labuhanbatu, Indonesia \\ ${ }^{6}$ Department of Management, Faculty of Economics and Business, Universitas Labuhanbatu, Labuhanbatu, Indonesia
}

Received 11 April 2020; Accepted 8 May 2020; Published 25 June 2020

\begin{abstract}
The oil palm empty fruit bunches are solid waste produced from the processing of oil palms which have a large amount of potential to be used as compost and are expected to improve the physical, biological and chemical properties of the subsoil. This study aimed to evaluate the best combination between oil palm empty fruit bunches compost and rice husk charcoal on soil chemical properties in tomato. This research was conducted in Sona Village, Labuhanbatu Regency in December 2019-March 2020. Analysis of soil chemical properties was conducted at the Socfind Seed Production and Laboratories (SSPL) Laboratory of PT. Socfin Indonesia. The study was conducted with a factorial randomized block design with 2 factors. The first factor was the application of oil palm empty bunches which consists of no oil palm empty bunches (control), $0.5 \mathrm{~kg} / \mathrm{polybag}, 0.7 \mathrm{~kg} / \mathrm{polybag}$ and $1 \mathrm{~kg} / \mathrm{polybag}$. The second factor was the application of rice husk charcoal which consists of non-husk charcoal (control), consisting of 0.2 $\mathrm{kg} /$ polybag and $0.4 \mathrm{~kg} /$ polybag. Data that had a significant effect after analysis of variance continued with DMRT at the level of $\alpha=5 \%$. The results showed that application of oil palm empty fruit bunches $(0.7 \mathrm{~kg} / \mathrm{polybag})$ significantly increased $\mathrm{pH}$ and $\mathrm{C}$-organic. Application of rice husk charcoal $(0.2 \mathrm{~kg} / \mathrm{polybag})$ significantly increased C-organic and P-available.
\end{abstract}

Keywords: C-organic; Organic substance; P-available

Cite This As (CSE Style): Harahap FS, Walida H, Rahmaniah, Rauf A, Hasibuan R, Nasution AP. 2020. Pengaruh Aplikasi Tandan Kosong Kelapa Sawit dan Arang Sekam Padi terhadap beberapa Sifat Kimia Tanah pada Tomat. Agrotech Res J. 4(1): 1-5. https://doi.org/10.20961/agrotechresj.v4i1.41121

\section{PENDAHULUAN}

Tanaman tomat (Lycopersicum esculentum Mill) merupakan tanaman komoditas pertanian yang mempunyai rasa manis dan asam yang unik, menjadikan tomat sebagai salah satu buah yang banyak digemari (Chaniago et al. 2017). Buah tomat juga banyak digunakan sebagai bahan baku industri, contohnya tomat segar dapat diolah menjadi saus, bahan pembuatan kosmetik, atau bahkan dapat digunakan sebagai bahan pembuatan obat-obatan. Buah tomat memiliki kandungan vitamin yang cukup lengkap sehingga buah tomat dipercaya dapat menyembuhkan berbagai penyakit (Tobing et al. 2018). Mengonsumsi buah tomat secara teratur dapat membantu mencegah

${ }^{*}$ Corresponding Author:

E-Mail: fitrasyawalharahap@gmail.com terserang penyakit kanker, terutama kanker prostat (Kartika 2010).

Untuk meningkatkan produktivitas lahan pertanian budidaya tanaman tomat usaha yang dilakukan tidak berbeda dengan budidaya tanaman pertanian lainya, yaitu dengan cara melakukan pemupukan menggunakan pupuk organik maupun pupuk anorganik. (Maryanto dan Rahmi 2015). Pemupukan di dalam kegiatan budi daya tanaman merupakan hal yang penting dengan tujuan memperbaiki kualitas dan kesehatan tanah (Nuro et al. 2016). Aplikasi pupuk organik dapat memperkaya kandungan bahan organik, hara makro-mikro sehingga dapat meningkatkan produksi (Zhou et al. 2013). Dalam budi daya sayuran penggunaan pupuk organik maupun anorganik dalam proses pemupukan telah banyak dilakukan. Mengingat harga pupuk kimia semakin mahal, penggunaan pupuk organik dapat dijadikan pilihan yang lebih baik (Lim dan Vimala 2012). Penggunaan pupuk organik juga dapat meningkatkan mikroorganisme tanah yang sangat 
bermanfaat dalam menyediakan unsur hara tanah dan memperbaiki lingkungan (Syawal et al. 2017). Upaya ini sekaligus untuk mengurangi penggunaan pupuk anorganik dikarenakan penggunaan pupuk anorganik yang berlebihan dapat menimbulkan dampak negatif terhadap lingkungan serta untuk menghemat biaya karena harga pupuk anorganik cenderung mahal (Harahap et al. 2019).

Pada perkebunan kelapa sawit salah satu bahan pupuk organik yang ketersediaannya masih banyak dan dapat diharapkan dapat menggantikan peran pupuk anorganik adalah tandan kosong kelapa sawit yang dapat dijadikan sebagai kompos. Tandan kosong kelapa sawit (TKKS) merupakan limbah padat yang dihasilkan dari proses pengolahan kelapa sawit, TKKS dengan jumlah yang banyak memiliki potensi untuk dapat dijadikan sebagai kompos serta diharapkan dapat memperbaiki sifat fisik, biologi dan kimia dari subsoil ultisol. Tandan kosong kelapa sawit memiliki komposisi kimia berupa selulosa 45,95\%, hemiselulosa 22,84\%, lignin $16,49 \%$, minyak $2,41 \%$ dan abu $1,23 \%$. Selama ini pemanfaatan limbah tandan kosong kelapa sawit sangat terbatas yaitu sebagai sumber kalium setelah proses pembakaran (Adiguna dan Aryantha 2020). Proses pembakaran tandan kosong kelapa sawit menghasilkan abu terbang yang dapat menimbulkan polusi udara. Hasil penelitian Toiby et al. (2016) menyatakan bahwa kompos TKKS mengandung hara $\mathrm{N}-$ Total $(6,79 \%), \mathrm{P}_{2} \mathrm{O}_{5}$ $(3,13 \%), \mathrm{K}_{2} \mathrm{O}(8,33 \%)$ dengan $\mathrm{pH} 9,59$ sedangkan hasil penelitian Andri dan Wawan (2017) menyatakan bahwa pemberian campuran $50 \mathrm{~g}$ kompos TKKS + $50 \mathrm{~g}$ cocopeat/tanaman meningkatkan tinggi bibit kelapa sawit secara nyata.

Pemanfaatan tandan kosong kelapa sawit ini antara lain sebagai sumber energi dan sebagai pupuk organik. Pada penelitian terdahulu, kombinasi aplikasi kompos tandan kosong kelapa sawit (TKKS) sebanyak 5 ton/ha dengan biomassa Chromolaena odorata sebanyak 10 ton/ha pada tanah Sulfaquent (sulfat masam) dapat meningkatkan $\mathrm{pH}$ dari 5,26 menjadi 6,22 (Hayat dan Andayani 2014). Penggunaan kompos tandan kosong kelapa sawit sebagai substitusi pupuk NPK dalam pembibitan awal kelapa sawit memberikan hasil analisis kompos tandan kosong kelapa sawit (TKKS) yaitu $\mathrm{N}=$ $1.40 \%, \mathrm{P}$ total $=0.96 \%, \mathrm{~K}=0.41 \%$, C-organik $=19.81$ $\%, \mathrm{pH}=7.8$, dan rasio $\mathrm{C} / \mathrm{N}=14.15$ (Agung et al. 2019). Keunggulan kompos TKKS meliputi kandungan kalium yang tinggi, tanpa penambahan starter dan bahan kimia, memperkaya unsur hara yang ada di dalam tanah, dan mampu memperbaiki sifat fisik, kimia dan biologi (Kesumaningwati 2015).

Hasil penelitian Harahap et al. (2019) menyatakan bahwa pemberian abu sekam padi 20 t/ha berpengaruh nyata dalam meningkatkan serapan $\mathrm{N}$ tanaman tetapi tidak berpengaruh nyata dalam meningkatkan tinggi tanaman, berat kering tanaman dan serapan $\mathrm{P}$ tanaman. Aplikasi pupuk organik dapat meningkatkan serapan hara, terutama $\mathrm{N}$, dengan mengurangi pencucian mineral. Blanco-Canqui et al. (2013) menambahkan akumulasi C-organik pada tanah dapat meningkatkan kemampuan tanah untuk menahan air selama periode kering dan menyerap air selama periode basah. Hasil penelitian Asih et al. (2019) menunjukkan bahwa residu kelapa sawit (tandan kosong) berpotensi sebagai salah satu sumber pupuk organik pada lahan kelapa sawit dan dapat diaplikasikan melalui kombinasi atau tanpa kombinasi dengan pupuk kandang dalam upaya meningkatkan kesuburan tanah ultisol. Hal ini sekaligus mengurangi biaya penggunaan pupuk kimia. Penelitian ini bertujuan untuk menentukan kombinasi terbaik antara kompos Tandan Kosong Kelapa Sawit (TKKS) dan arang sekam padi pada sifat kimia tanah pada tomat.

\section{BAHAN DAN METODE}

Penelitian ini dilakukan di Kampung Sona Kabupaten Labuhanbatu pada Desember 2019-Maret 2020. Analisa sifat kimia tanah dilakukan di Laboratorium Kimia dan Kesuburan Tanah Fakultas Pertanian, Universitas Sumatera Utara, serta Socfindo Seed Production and Laboratories (SSPL) Kebun Bangun Bandar PT. Socfin Indonesia. Penelitian dilakukan dengan rancangan acak kelompok faktorial. Faktor pertama tandan kosong kelapa sawit yaitu $\mathrm{S}_{0}$ : tanpa tandan kosong kelapa sawit (kontrol), $S_{1}: 0,5 \mathrm{~kg} /$ polybag, $\mathrm{S}_{2}: 0,7 \mathrm{~kg} /$ polybag dan $\mathrm{S}_{3}$ : $1 \mathrm{~kg} /$ polybag. Faktor yang kedua arang sekam padi yaitu $\mathrm{P}_{0}$ : tanpa arang sekam (kontrol), $\mathrm{P}_{1}$ : 0,2 kg/polybag dan $\mathrm{P}_{2}$ : 0,4 kg/polybag. Jumlah kombinasi perlakuan adalah 12 kombinasi. Uji lanjut yang digunakan adalah Duncan Multiple Range Test (DMRT) (Gomez, K. A. dan Gomez 1995). Adapun parameter yang diamati yaitu sifat kimia tanah meliputi $\mathrm{pH}$ tanah Metode Elektrometri, C-organik (\%) Metode Walkley and Black, P-Tersedia (\%) Metode Bray II.

\section{HASIL DAN PEMBAHASAN \\ Kesuburan Tanah}

Hasil analisis sampel tanah awal di Kampung Sona menunjukkan bahwa kandungan $\mathrm{pH} \quad\left(\mathrm{H}_{2} \mathrm{O}\right) \quad 4,20$ tergolong masam, kandungan $\mathrm{P}_{2} \mathrm{O}_{5}$ Bray II (ppm) dan $\mathrm{K}(\mathrm{mg} / 100 \mathrm{~g})$ masing-masing adalah 8,63 ppm dan 23,64 $\mathrm{mg} / 100 \mathrm{~g}$ tergolong sedang. Sedangkan C-organik $1,54 \%$ dan kandungan $\mathrm{N}$-total $0,27 \%$ tergolong rendah sehingga diperoleh nisbah $\mathrm{C}: \mathrm{N}$ yaitu 5,70 .

Kandungan hasil analisa tandan kosong kelapa sawit memiliki kandungan $\mathrm{pH}\left(\mathrm{H}_{2} \mathrm{O}\right) 6,45$, kandungan $\mathrm{P}$ (total) $1,54 \%$ dan $\mathrm{K}$ (total) $1,42 \%$. Tandan kosong kelapa sawit ini memiliki kandungan C-organik 16,55\% dan kandungan $\mathrm{N}$-total $0,97 \%$ nisbah C:N bernilai 17,06 sedangkan arang sekam padi berdasarkan hasil analisis awal memiliki kandungan $\mathrm{pH}\left(\mathrm{H}_{2} \mathrm{O}\right) 5,15$, kandungan $\mathrm{P}$ (total) dan $\mathrm{K}$ (total), masing-masing adalah $1,83 \%$, dan $1,48 \%$. Kandungan hasil analisa arang sekam padi memiliki kandungan C-organik 18,45\% dan kandungan N-total 1,07\% nisbah C:N yaitu 17.24.

Berdasarkan nilai $\mathrm{pH}$ diketahui bahwa nilai $\mathrm{pH}$ tandan kosong kelapa sawit dan arang sekam padi lebih tinggi bila dibandingkan dengan nilai $\mathrm{pH}$ tanah sehingga diharapkan dengan meningkatkan nilai $\mathrm{pH}$ tanah maka akan berpengaruh terhadap perbaikan sifat fisik, kimia dan biologinya. Menurut Peraturan Menteri Pertanian (2011), pupuk organik siap untuk digunakan apabila nilai C-organik $\geq 15 \%$ dengan nisbah C:N berkisar antara $15-$ 25. 


\section{pH Tanah}

Pengaruh pemberian tandan kosong kelapa sawit dan arang sekam padi terhadap $\mathrm{pH}$ tanah dapat dilihat pada Tabel 1. Arang sekam padi serta interaksi tandan kosong kelapa sawit tidak berpengaruh nyata terhadap $\mathrm{pH}$ tanah, sedangkan tandan kosong kelapa sawit berpengaruh nyata terhadap $\mathrm{pH}$ tanah (Tabel 1).

Berdasarkan hasil uji beda rataan pada Tabel 1 menunjukkan bahwa aplikasi tandan kosong kelapa sawit $S_{0}$ (kontrol) berbeda nyata dengan semua taraf lainnya $\left(S_{1}, S_{2}\right.$, dan $\left.S_{3}\right)$. Taraf $S_{1}$ berbeda nyata dengan taraf $S_{2}$ dan $S_{3}$, sedangkan taraf $S_{2}(0,7 \mathrm{~kg} /$ polybag $)$ tidak berbeda nyata dengan taraf $S_{3}(1 \mathrm{~kg} /$ polybag $)$. Pada pemberian tandan kosong kelapa sawit, $\mathrm{pH}$ tertinggi terdapat pada taraf $\mathrm{S}_{2}(5,03)$ dan yang terendah pada taraf $\mathrm{S}_{0}(4,47)$. Peningkatan $\mathrm{pH}$ tanah dipengaruhi oleh rendahnya $\mathrm{pH}$ pada tanah Ultisol di Kampung Sona Kabupaten Labuhanbatu yakni berkisar 4,20 yang tergolong masam. Arang sekam padi menghasilkan nilai rata-rata $\mathrm{pH}$ tanah 4,76-4,79 dengan kriteria bersifat masam. Hal ini diduga bahwa arang sekam padi dan tandan kosong kelapa sawit mengandung bahan organik yang membuat $\mathrm{pH}$ tanah menjadi masam. Hasil ini didukung oleh pendapat Pane et al. (2014) yang menyatakan bahwa pemberian bahan organik pada tanah yang bersifat masam, seperti tanah ultisol, dapat meningkatkan $\mathrm{pH}$ tanah. Secara umum, bahan organik tanah memiliki peranan yang penting dalam siklus karbon dan hara dan perubahan $\mathrm{pH}$ tanah (Wang et al. 2013). Arang sekam padi pada tanah juga membantu ketersediaan $\mathrm{K}$ dan meningkatkan serapan $\mathrm{P}$, Ca dan $\mathrm{Mg}$ oleh tanaman. Kandungan unsur tersebut sebagai pengganti kapur mampu meningkatkan $\mathrm{pH}$ tanah, sehingga unsur hara dapat tersedia bagi tanaman (Tarigan et al. 2015).

\section{C-organik (\%)}

Pengaruh pemberian tandan kosong kelapa sawit dan arang sekam padi terhadap C-organik dapat dilihat pada Tabel 2. Interaksi tandan kosong kelapa sawit dan arang sekam padi tidak berpengaruh nyata terhadap Corganik. Pemberian arang sekam padi berpengaruh nyata terhadap C-organik, sedangkan aplikasi tandan kosong kelapa sawit berpengaruh nyata terhadap Corganik (Tabel 2).

C-organik tanah tertinggi pada interaksi tandan kosong kelapa sawit dan arang sekam padi yaitu pada taraf $\mathrm{S}_{3} \mathrm{P}_{1}(1,97 \%)$ dan terendah pada taraf $\mathrm{S}_{0} \mathrm{P}_{1}(1,04$ $\%)$. Peningkatan kandungan $\mathrm{C}$-organik yang terdapat di dalam tanah Ultisol disebabkan tandan kosong kelapa sawit merupakan pupuk yang berbahan organik dan memiliki kandungan $\mathrm{C}$-organik yang tinggi. Pemberian bahan organik berupa tandan kosong kelapa sawit (TKKS), serabut kelapa sawit dan kombinasi keduanya selama 12 minggu inkubasi meningkatkan kadar Corganik tanah bila dibandingkan dengan kondisi awal sebelum perlakuan. Hal ini sesuai dengan Hakim et al. (1986) yang menyatakan bahwa dekomposisi bahan organik akan terganggu pada tanah masam proses, sehingga akan menghambat pembebasan karbon dari bahan organik juga. Aktivitas mikroorganisme akan meningkat ketika dilakukan penambahan bahan organik dan juga meningkatnya proses perombakan bahan organik yang menghasilkan karbon (Yunindanova et al. 2014). Hasil penelitian ini sejalan dengan penelitian Darmosarkoro dan Winarna (2001) yang menyatakan bahwa kompos tandan kosong kelapa sawit yang dihasilkan oleh pabrik kelapa sawit merupakan sumber hara potensial. Kompos tandan kosong kelapa sawit memiliki kandungan karbon yang tinggi yang berfungsi sebagai bahan pembenah tanah.

Tabel 1. $\mathrm{pH}$ tanah dengan pemberian tandan kosong kelapa sawit dan arang sekam padi

\begin{tabular}{lcccc}
\hline \multirow{2}{*}{$\begin{array}{l}\text { Tandan kosong } \\
\text { kelapa sawit }\end{array}$} & \multicolumn{3}{c}{ Arang Sekam Padi } & Rataan \\
\cline { 2 - 4 } & $\mathrm{P}_{0}$ & $\mathrm{P}_{1}$ & $\mathrm{P}_{2}$ & \\
\hline $\mathrm{S}_{0}$ & 4,41 & 4,27 & 4,59 & $4,47 \mathrm{c}$ \\
$\mathrm{S}_{1}$ & 4,57 & 4,55 & 4,69 & $4,66 \mathrm{~b}$ \\
$\mathrm{~S}_{2}$ & 5,11 & 4,94 & 5,03 & $5,03 \mathrm{a}$ \\
$\mathrm{S}_{3}$ & 4,80 & 5,04 & 4,91 & $4,91 \mathrm{a}$ \\
\hline Rataan & 4,72 & 4,70 & 4,80 & \\
\hline
\end{tabular}

Keterangan: angka diikuti huruf sama pada baris dan kolom sama tidak berbeda nyata berdasarkan uji DMRT pada taraf $5 \%$

Tabel 2. C-organik (\%) dengan pemberian tandan kosong kelapa sawit dan arang sekam padi

\begin{tabular}{lcccc}
\hline \multirow{2}{*}{$\begin{array}{l}\text { Tandan kosong } \\
\text { kelapa sawit }\end{array}$} & \multicolumn{4}{c}{ Arang Sekam Padi } \\
\cline { 2 - 4 } & $\mathrm{P}_{0}$ & $\mathrm{P}_{1}$ & $\mathrm{P}_{2}$ & \\
\hline $\mathrm{S}_{0}$ & 1,24 & 1,04 & 1,11 & $1,15 \mathrm{c}$ \\
$\mathrm{S}_{1}$ & 1,64 & 1,54 & 1,37 & $1,48 \mathrm{~b}$ \\
$\mathrm{~S}_{2}$ & 1,59 & 1,79 & 1,54 & $1,62 \mathrm{ab}$ \\
$\mathrm{S}_{3}$ & 1,92 & 1,97 & 1,42 & $1,78 \mathrm{a}$ \\
\hline Rataan & $1,49 \mathrm{~b}$ & $1,60 \mathrm{a}$ & $1,59 \mathrm{a}$ & \\
\hline
\end{tabular}

Keterangan: angka diikuti huruf sama pada baris dan kolom sama tidak berbeda nyata berdasarkan uji DMRT pada taraf $5 \%$

\section{P-tersedia (ppm)}

Pengaruh pemberian tandan kosong kelapa sawit dan arang sekam padi terhadap P-Tersedia (ppm) dapat dilihat dari pada Tabel 3. Aplikasi tandan kosong kelapa sawit serta interaksinya dengan arang sekam padi tidak berpengaruh nyata terhadap P-tersedia, sedangkan aplikasi tandan kosong kelapa sawit berpengaruh nyata terhadap P-tersedia. Aplikasi arang sekam padi pada taraf $\mathrm{P}_{0}$ (kontrol) berbeda nyata dengan $\mathrm{P}_{1}$ dan $\mathrm{P}_{2}$ (Tabel $3)$.

P-tersedia tertinggi pada interaksi tandan kosong kelapa sawit dan arang sekam padi yaitu $\mathrm{S}_{1} \mathrm{P}_{2}(2,73$ $\mathrm{ppm})$ dan terendah pada $\mathrm{S}_{0} \mathrm{P}_{0}(1,54 \mathrm{ppm})$. Dari hasil penelitian ini terlihat bahwa pemberian pupuk kompos tandan kosong kelapa sawit dan arang sekam dapat menyumbangkan unsur hara $\mathrm{P}$ ke dalam tanah. Hal ini menyebabkan unsur hara $\mathrm{P}$ menjadi tersedia dalam tanah dan mengalami peningkatan dari $1,54 \mathrm{ppm}$ menjadi 2,73 ppm. Hal ini sesuai dengan pendapat Haitami and Wahyudi (2019) yang menyatakan bahwa dengan pemberian pupuk kompos tandan kosong kelapa sawit dapat menyumbangkan unsur hara $P$ ke dalam 
tanah. Hal ini menyebabkan unsur hara $P$ menjadi tersedia dalam tanah dan mengalami peningkatan dari 2,27 ppm menjadi 101,41 ppm. Hal ini sejalan dengan pendapat Harahap et al. (2020) yang menyatakan bahwa unsur $\mathrm{P}$ tersedia di dalam tanah bisa disebabkan karena adanya bahan organik di tanah tersebut, baik secara langsung ataupun dengan proses mineralisasi, atau dengan perlakuan yang diberikan sehingga dapat melepaskan $\mathrm{P}$ yang terfiksasi.

Tabel 3. P-Tersedia (ppm) dengan pemberian tandan kosong kelapa sawit dan arang sekam padi

\begin{tabular}{lcccc}
\hline \multirow{2}{*}{$\begin{array}{l}\text { Tandan kosong } \\
\text { kelapa sawit }\end{array}$} & \multicolumn{4}{c}{ Arang Sekam Padi } \\
\cline { 2 - 4 } & $\mathrm{P}_{0}$ & $\mathrm{P}_{1}$ & $\mathrm{P}_{2}$ & \\
\hline $\mathrm{S}_{0}$ & 1,54 & 2,69 & 2,68 & 1,88 \\
$\mathrm{~S}_{1}$ & 2,11 & 2,67 & 2,73 & 2,16 \\
$\mathrm{~S}_{2}$ & 2,16 & 2,24 & 2,71 & 2,07 \\
$\mathrm{~S}_{3}$ & 2,24 & 2,43 & 2,72 & 2,14 \\
\hline Rataan & $2,01 \mathrm{~b}$ & $2,51 \mathrm{a}$ & $2,71 \mathrm{a}$ & \\
\hline
\end{tabular}

Keterangan: angka-angka yang diikuti oleh huruf yang sama berarti berbeda tidak nyata $(5 \%)$ menurut uji DMRT pada taraf $5 \%$

\section{KESIMPULAN}

Pemberian tandan kosong kelapa sawit sebanyak 0,7 $\mathrm{kg} /$ polybag mampu meningkatkan $\mathrm{pH}$ tanah dan $\mathrm{C}$ organik. Pemberian 0,2 kg/polybag arang sekam padi mampu meningkatkan P-tersedia dan C-organik.

\section{DAFTAR PUSTAKA}

Adiguna GS, Aryantha INP. 2020. Aplikasi fungi rizosfer sebagai pupuk hayati pada bibit kelapa sawit dengan memanfaatkan limbah tandan kosong kelapa sawit sebagai media pertumbuhan. Manfish J. 1(1):32-42.

Agung AK, Adiprasetyo TA, Hermansyah H. 2019. Penggunaan kompos tandan kosong kelapa sawit sebagai subtitusi pupuk npk dalam pembibitan awal kelapa sawit. J IImu-IImu Pertan Indones. 21(2):7581. Doi:10.31186/Jipi.21.2.75-81.

Andri RK, Wawan W. 2017. Pengaruh pemberian beberapa dosis pupuk kompos (greenbotane)terhadap pertumbuhan bibit kelapa sawit ( Elaeis quieneensis Jacq) di pembibitan utama. J Online Mhs Fak Pertan Univ Riau. 4(2):1-14.

Asih PW, Utami SR, Kurniawan S. 2019. Perubahan Sifat kimia tanah setelah aplikasi tandan kosong kelapa sawit pada dua kelas tekstur tanah. J Tanah Dan Sumberd Lahan. 6(2):1313-1323. Doi:10.21776/Ub.Jtsl.2019.006.2.12.

Blanco-Canqui $\mathrm{H}$, Shapiro CA, Wortmann CS, Drijber RA, Mamo M, Shaver TM, Ferguson RB. 2013. Soil organic carbon: the value to soil properties. J Soil Water Conserv. 68(5). Doi:10.2489/Jswc.68.5.129a.

Chaniago N, Safruddin, Kurniawan D. 2017. Respon pertumbuhan dan produksi tanaman tomat (Lycopersicum esculentum Mill) terhadap Pemberian pupuk kandang sapi dan fermentasi urin sapi. J Penelit Pertan Bernas. 13(1):23-29. http://jurnal.una.ac.id/index.php/jb/article/view/85.
Darmosarkoro, Winarna. 2001. Penggunaan tandan kelapa sawit dan kompos tandan kelapa sawit untuk meningkatkan pertumbuhan dan produksi tanaman. Prosiding: Lahan Dan Pemupukan Kelapa Sawit. In: Witjaksana D, S. Es, Winarna, Editors. Prosiding: Lahan dan pemupukan kelapa sawit. medan: pusat penelitian kelapa sawit. P. 187-200.

Gomez, K. A, Gomez Aa. 1995. Prosedur Statistika untuk penelitian pertanian edisi kedua.

Haitami A, Wahyudi W. 2019. Pengaruh berbagai dosis pupuk kompos tandan kosong kelapa sawit plus (kotakplus) dalam memperbaiki sifat kimia tanah ultisol. J IIm Pertan. 16(1):56-63. Doi:10.31849/Jip.V16i1.2351.

Hakim N, Nyakpa MY, Lubis AM, Nugroho SG, Saul MR, Diha MA, Hong G, Bailey HH. 1986. Dasar-dasar ilmu tanah. Univ Lampung Lampung. 488.

Harahap FS, Walida H, Harahap DA, Wicaksono M. 2019. Pemberian abu sekam padi dan jerami padi untuk pertumbuhan serta serapan tanaman jagung manis (Zea mays L.) pada tanah ultisol di kecamatan rantau selatan. J Agroplasma. 6(2):12-18. Doi:10.36987/Agr.V6i2.675.

Harahap FS, Walida $H$, Dalimunthe BA, Rauf A, Sidabuke SH, Hasibuan R. 2020. The use of municipal solid waste composition in degradated waste soil effectiveness in aras kabu village, beringin subdistrict, deli serdang district. Agrinula. 3(1):19-27.

Hayat E, Andayani S. 2014. Pengelolaan limbah tandan kosong kelapa sawit dan aplikasi biomassa Chromolaena odorata terhadap pertumbuhan dan hasil tanaman padi serta sifat tanah sulfaquent. $J$ Teknol Pengelolaan Limbah.

Kartika R. 2010. Pengaruh penambahan Caco3 dan waktu penyimpanan terhadap kadar vitamin c pada proses penghambatan pematangan buah tomat (Lycopersicum esculentum Mill). J Kim Mulawarman.

Kesumaningwati R. 2015. Penggunaan mol bonggol pisang (Musa paradisiaca) sebagai dekomposer untuk pengomposan tandan kosong kelapa sawit. Ziraa'ah Maj IIm Pertan. Doi:10.31602/Zmip.V40i1.96.

Lim AH, Vimala P. 2012. Growth and yield responses of four leafy vegetables to organic fertilizer. J Trop Agric Food Sci. 40(1):1-11. http://jtafs.mardi.gov.my/jtafs/401/Four\%20leafy\%20vegetables.pdf.

Maryanto, Rahmi A. 2015. Pertumbuhan dan hasil tanaman tomat ( Lycopersicum esculentum Mill ) varietas permata tanaman tomat. Agrifor.

Nuro F, Priadi D, Mulyaningsih Es. 2016. Efek pupuk organik terhadap sifat kimia tanah dan produksi kangkung darat (Ipomoea reptans Poir.). Pros Semin Nas Hasil-Hasil PPM IPB 2016.:29-39.

Pane M, Damanik M, Sitorus B. 2014. Pemberian bahan organik kompos jerami padi dan abu sekam padi dalam memperbaiki sifat kimian tanah ultisol serta pertumbuhan tanaman jagung. J Agroekoteknologi Univ Sumatera Utara. 2(4):101546. Doi:10.32734/Jaet.V2i4.8438. 
Permentan. 2011. Peraturan menteri pertanian nomor 70/peraturan menteri pertanian republik indonesia/Sr.140/10/2011 Tentang Pupuk Organik, Pupuk Hayati Dan Pembenah Tanah.

Syawal F, Rauf A, Rahmawaty. 2017. Upaya Rehabilitasi Tanah Sawah Terdegradasi Dengan Menggunakan Kompos Sampah Kota Di Desa Serdang Kecamatan Beringin Kabupaten Deli Serdang. J Pertan Trop. 4(3):183-189. Doi: 10.32734/jpt.v4i3.3089 .

Tarigan E, Hasanah Y, Mariati. 2015. Respons Pertumbuhan Dan Produksi Bawang Merah (Allium Ascalonicum L.) Terhadap Pemberian Abu Vulkanik Gunung Sinabung Dan Arang Sekam Padi. J Online Agroekoteknologi. 3(3):956-962.

Tobing Jhl, Suwitono Mr, Sihotang A, Biologi J, Matematika F, Advent U, Unai I, Kolonel J. 2018. Kemampuan Tumbuh Tanaman Tomat ( Solanum Lycopersicum L .). J Sains Dan Teknol Indones. 1(2):1-6.

Toiby Ar, Rahmadani E, Oksana O. 2016. Perubahan sifat kimia tandan kosong kelapa sawit yang difermentasi dengan em4 pada dosis dan lama pemeraman yang berbeda. J Agroteknologi. 6(1):1. Doi:10.24014/Ja.V6i1.1370.

Wang Y, Liu X, Butterly C, Tang C, Xu J. 2013. Ph Change, carbon and nitrogen mineralization in paddy soils as affected by chinese milk vetch addition and soil water regime. J Soils Sediments. 13(4):654-663. Doi:10.1007/S11368-012-0645-3.

Yunindanova MB Agusta H, Asmono D. 2014. Pengaruh tingkat kematangan kompos tandan kosong sawit dan mulsa limbah padat kelapa sawit terhadap produksi tanaman tomat (Lycopersicon esculentum Mill.) pada tanah ultisol. Sains Tanah-Journal Soil Sci Agroclimatol. 10(2):91-100.

Zhou H, Peng X, Perfect E, Xiao T, Peng G. 2013. Effects of organic and inorganic fertilization on soil aggregation in an ultisol as characterized by synchrotron Based X-Ray Micro-Computed Tomography. Geoderma. 195-196(March):23-30. Doi:10.1016/J.Geoderma.2012.11.003. 